\title{
Distribution Prediction Correction Based on the Analysis of Job/Housing Balance between Old and New Districts
}

\author{
Tao Li ${ }^{1}$, Hai Yan ${ }^{2}$ \\ ${ }^{1}$ College of Architectural Engineering, Beijing University of Technology, Beijing, China \\ ${ }^{2}$ College of Metropolitan Transportation, Beijing University of Technology, Beijing, China \\ Email: taoli0505@emails.bjut.edu.cn,yhai@bjut.edu.cn
}

How to cite this paper: Li, T. and Yan, H. (2017) Distribution Prediction Correction Based on the Analysis of Job/Housing Balance between Old and New Districts. Open Journal of Applied Sciences, 7, 57-67. https://doi.org/10.4236/ojapps.2017.72006

Received: January 9, 2017

Accepted: February 13, 2017

Published: February 16, 2017

Copyright (c) 2017 by authors and Scientific Research Publishing Inc. This work is licensed under the Creative Commons Attribution International License (CC BY 4.0).

http://creativecommons.org/licenses/by/4.0/ (c) (i) Open Access

\begin{abstract}
The cities of China are in the period of rapid development of urbanization. The practical problems, which faced by urban traffic planning, include an effective prediction for the traffic volume. This paper, combining the example of Cangzhou's traffic planning, analyzes the differences on land use between the new and the old district, including its influence to the residents. It also analyzes the relationship of travel features and the coefficient of job/housing balance in the new and the old district; furthermore, it corrects the result of traditional gravity model by using balance's coefficient. Through this study, we find that the corrected model deals with the problem of travel forecasting's deviation, which is closer to the physic truth. In the meanwhile, we suggested paying more attention to the relationship of land use and housing/jobs in the district plan, in this way, it will reduce the traffic demand radically and optimize the traffic structure.
\end{abstract}

\section{Keywords}

Traffic Planning, Job/Housing Balance, Gravity Mode, Balance Coefficient

\section{Introduction}

Employment and residence are two basic elements of urban land use patterns, and the spatial relationship between these two elements has largely determined the characteristics and efficiency of urban transport. Therefore, how to properly conduct employment and living arrangements has become a central and permanent issue of urban planning.

The planning concept of job/housing balance dates back to Howard's Garden City in late 19th century. He points out that the garden city should equip service 
facilities. Balanced distribution of employment and residence, the people work in factories within walking distance [1].

Job/housing research focused on two parts at home and abroad. One part is the research of effective job/housing balance policy. Whether job/housing balance policy is valid, mainly depends on if the city's transportation efficiency is improved after job/housing balance in one area [2] [3] [4] [5]. In other word, residents' commuting time and distance are shortened, thereby, reducing traffic congestion and air pollution. Scholars usually use growth rate and gravity model approaches to forecast traffic demand that mainly considers trip generation, trip attraction and impedance between each two traffic zones [6]-[13]. However, they make little consideration on the impact of job/housing balance.

This paper uses residents travel survey of Cangzhou as primary data sources. And it makes study on the impact of the residents travel through differences in land consisting of new and old town, so that determines the job/housing balance's coefficient by the situation of employment-residence balance. It uses coefficient of job/ housing balance to correct OD matrix predicted by gravity models. Finally, it provides rationalization proposals for city expansion.

\section{Data Analysis}

\subsection{Research Object and Data Sources}

This data comes from trip survey of comprehensive transportation planning in Cangzhou. Scope of the investigation is permanent residents and temporary residents within the boundary of Cangzhou. During the home visits, make a sample survey of residents in 4000 households (approximately 12,000 people). Select the survey time from Tuesday to Thursday (non-holiday, no activities of major regional or citywide, etc.), and the day's weather is normal (no inclement weather that has significant effect on travel characteristics).

The questionnaire has three parts which include personal characteristics, family characteristics, and characteristics of trips. Make investigation on daily number of trips, travel destination, travel mode, travel time and other features.

\subsection{Traffic Zone Division}

According to the principle of transportation planning, divided 59 traffic zones in order to analyze residents trip characteristics and prepare for the residents travel forecasting. Among them, the main city has 47 traffic zones including 4 west district, a development area and 7 external districts. Traffic zones distribution as shown in Figure 1.

Since some neighboring regions with similar land structure, and therefore, we should merge some traffic zones into middle zones (Table 1 ) for analyzing resident trip characteristics of new and old town (exclude external zones). There are three middle zones (middle zones $1,2,3$ ) in west district, three middle zones (middle zones $4,5,6$ ) in old district while middle zone 7 in east district. 


\subsection{Trip Analysis of New/Old Town}

Calculate the proportion of residential land area in each middle zone (Table 2).

As can be seen from the table, the residential proportion of old town is higher than new town. In particular, Zone 5's proportion is $43.7 \%$, nearly reaches $50 \%$. There is no house in middle zone 1 , because it is industrial land.

Existing research on measure of job/housing balance coefficient include two parts: number balance and mass balance. The former refers to whether the number of jobs is equal to the number of residential units in a given geographical area, as called balance degree measurements while the latter one refers to the

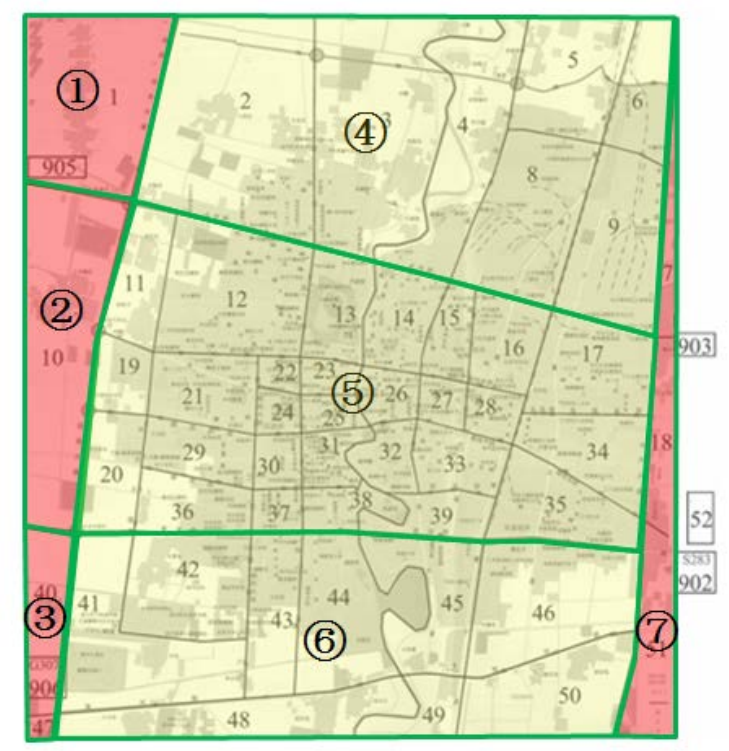

Figure 1. Distribution of traffic zones.

Table 1. Correspondence between traffic zones and middle zones.

\begin{tabular}{ccc}
\hline Middle zone NO. & Traffic zone NO. & New/Old town \\
\hline 1 & 1 & New \\
2 & 10 & New \\
3 & 40,47 & New \\
4 & $2,3,4,5,6,8,9$ & Old \\
5 & $11,12,13,14,15,16,17,19,20,21,22,23,24,25$, & Old \\
6 & $26,27,28,29,30,31,32,33,34,35,36,37,38,39$ & Old \\
7 & $41,42,43,44,45,46,48,49,50$ & New \\
\hline
\end{tabular}

Table 2. The proportion of residential land.

\begin{tabular}{cccccccc}
\hline Middle zone NO. & 1 & 2 & 3 & 4 & 5 & 6 & 7 \\
\hline Size of residential land $\left(\mathrm{km}^{2}\right)$ & 0 & 2.8 & 3.1 & 4.1 & 10.2 & 3.8 & 5.7 \\
Size of middle zones $\left(\mathrm{km}^{2}\right)$ & 8.2 & 19.4 & 10.1 & 16.7 & 23.3 & 12.3 & 33.9 \\
Proportion & $0.0 \%$ & $14.5 \%$ & $30.7 \%$ & $24.8 \%$ & $43.7 \%$ & $31.1 \%$ & $16.8 \%$ \\
\hline
\end{tabular}


proportion of the number of workers who live and work in the same area, which called self-contained measurements.

We can infer that the closer to 1:1 of residential land and other land area ratio, the better job/housing balance. So the balance of old town district (middle zones $4,5,6$ ) is better than the new town district (middle zones $1,2,3$ ).

Calculate the OD matrix according to four-stage and extract traffic occurs volume and volume within zone (Table 3 ).

As can be seen from the table, the proportion of regional travel in old towns is higher than the new ones. Combined with land use patterns we can see in Figure 2 .

The proportion of regional travel in old towns (Zones 4, 5, 6) is higher than the new ones (Zones 1, 2, 3, and 7) while the proportion of residential land area is also higher. This is because the job/housing balance of old towns is better than the new ones, so that residents can travel in their region which is the complete daily activities. Therefore, the better degree of balance is the higher proportion of traffic volume within zone.

Census each middle zone's average travel time shows in Figure 3. We can see that the average travel time in old towns is about 20 minutes while it is $25 \mathrm{mi}-$ nutes in new ones. In particular, average travel time in middle zone 3 is $36 \mathrm{mi}$ nutes. The old towns' travel time is less than the new ones because of the better degree of balance.

Census the proportion of each travel modes in middle zones which respectively shown in Table 4. As can be seen from the table, the main travel modes in

Table 3. The proportion of traffic volume internal.

\begin{tabular}{cccccccc}
\hline Middle zones NO. & 1 & 2 & 3 & 4 & 5 & 6 & 7 \\
\hline Traffic generation & 131,957 & 264,790 & 135,760 & 244,016 & $1,929,575$ & 223,535 & 98,981 \\
Internal travel & 0 & 66,924 & 38,012 & 103,839 & $1,641,044$ & 74,617 & 17,214 \\
Proportion & $0.0 \%$ & $25.3 \%$ & $28.0 \%$ & $42.6 \%$ & $85.0 \%$ & $33.4 \%$ & $17.4 \%$ \\
\hline
\end{tabular}

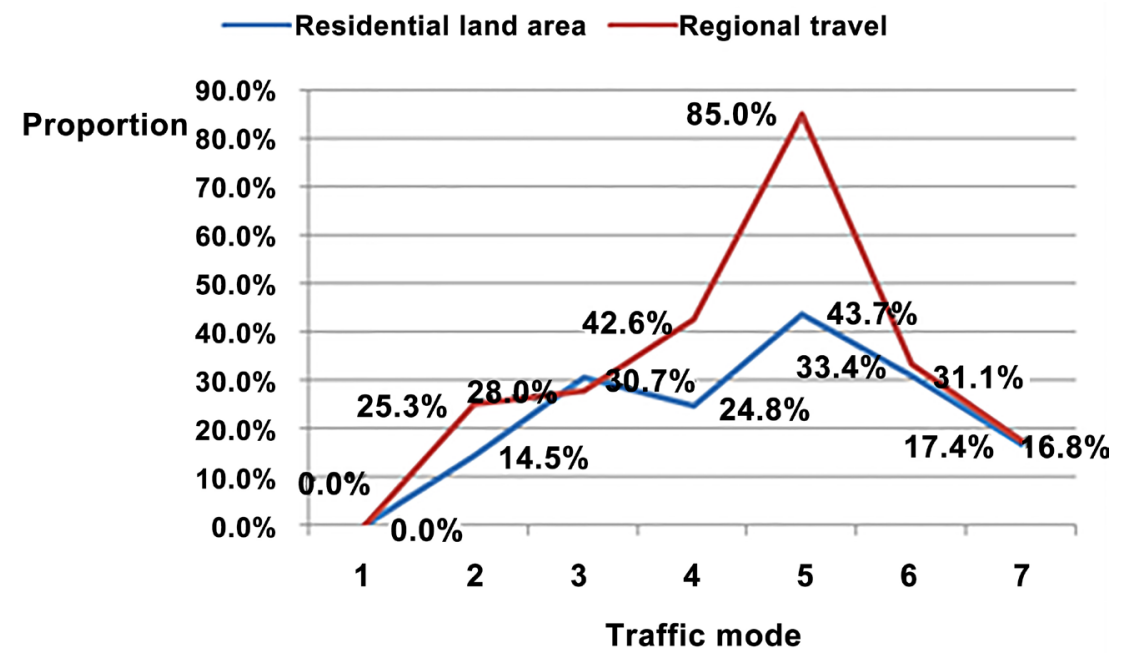

Figure 2. Residential land and regional travel corresponds to figure. 


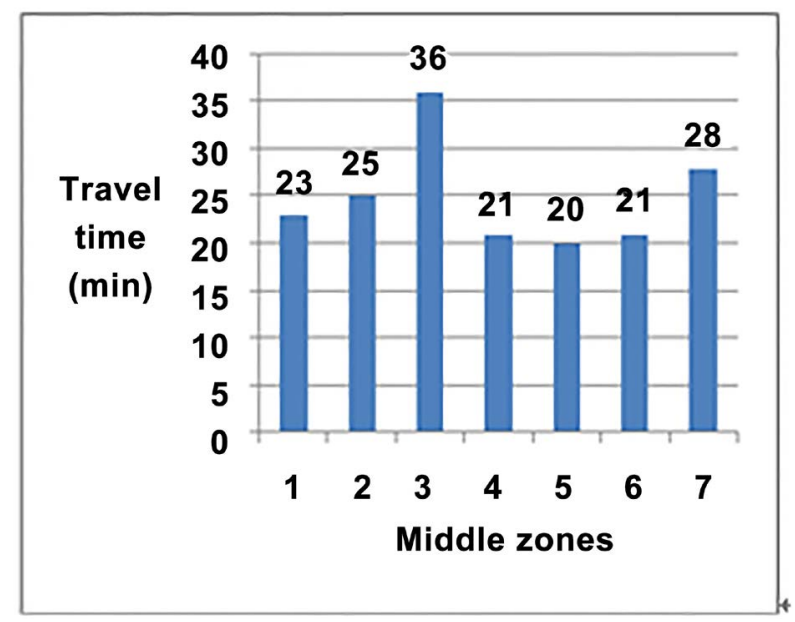

Figure 3. Average travel time in each middle zone.

Table 4. The proportion of travel modes in each middle zone.

\begin{tabular}{cccccccc}
\hline Travel mode & Zone 1 & Zone 2 & Zone 3 & Zone 4 & Zone 5 & Zone 6 & Zone 7 \\
\hline Pedestrian & $19 \%$ & $13 \%$ & $1 \%$ & $21 \%$ & $25 \%$ & $18 \%$ & $4 \%$ \\
Bicycle & $29 \%$ & $14 \%$ & $13 \%$ & $35 \%$ & $36 \%$ & $34 \%$ & $16 \%$ \\
Electric bicycle & $22 \%$ & $38 \%$ & $32 \%$ & $22 \%$ & $23 \%$ & $26 \%$ & $54 \%$ \\
Motorcycle & $2 \%$ & $12 \%$ & $1 \%$ & $4 \%$ & $3 \%$ & $4 \%$ & $4 \%$ \\
Private car & $7 \%$ & $5 \%$ & $8 \%$ & $3 \%$ & $3 \%$ & $4 \%$ & $4 \%$ \\
Enterprise car & $1 \%$ & $1 \%$ & $0 \%$ & $1 \%$ & $1 \%$ & $1 \%$ & $1 \%$ \\
Shuttle units & $13 \%$ & $1 \%$ & $14 \%$ & $3 \%$ & $1 \%$ & $1 \%$ & $9 \%$ \\
Bus & $6 \%$ & $11 \%$ & $26 \%$ & $6 \%$ & $5 \%$ & $6 \%$ & $7 \%$ \\
Taxi & $0 \%$ & $2 \%$ & $4 \%$ & $1 \%$ & $1 \%$ & $2 \%$ & $1 \%$ \\
Others & $1 \%$ & $1 \%$ & $0 \%$ & $3 \%$ & $3 \%$ & $4 \%$ & $2 \%$ \\
\hline
\end{tabular}

each middle zone are Pedestrian, Bicycle, Electric Bicycle and Bus. The proportion of Private Car in new town is higher than old town so is Shuttle Units. This is because new towns are dominated by industrial land and public transport is not perfect, so that commuter travel prefer to use private cars and shuttle units.

Census the proportion of main traffic mode (Pedestrian, Bicycle, Electric Bicycle, Bus) is in each middle zone. The results show in Figure 4.

The figure shows that the proportion of old town district residents in walking, bicycle and public transportation is higher than the metro area. This is due to the old town's job/housing balance. It is better than the new town, so that the travel distance becomes shorter and travel modes tend to use pedestrian and bicycle traffic and public transport.

We calculated the average travel time of each middle traffic zone. The results show in Figure 5. As can be seen from the figure, the average daily number of trips in old town districts is higher than metro area because of the degree of job/housing balance. Besides daily commuters, other trip purposes' proportion of residents in old towns is higher than metro zones. Various facilities in new towns are not 


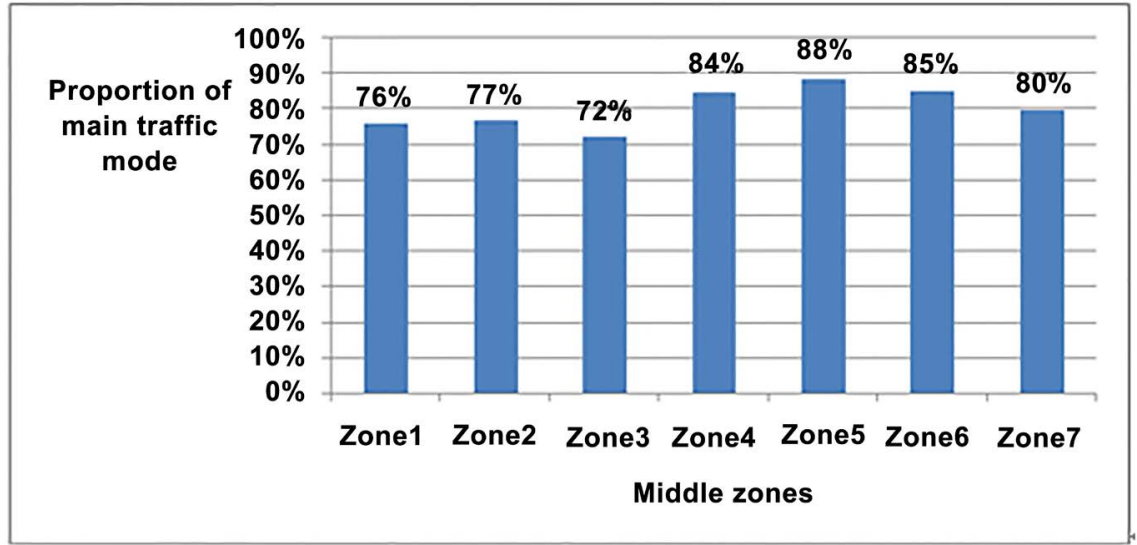

Figure 4. The percentage of main traffic mode in each middle zone.

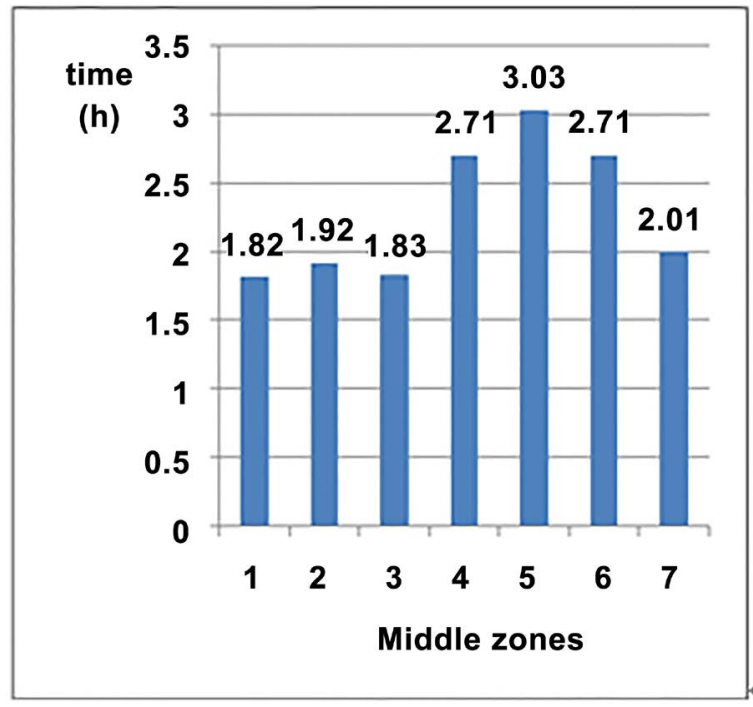

Figure 5. Average time of travel in each middle zone.

perfect, then purpose in new towns dominated by commuter traffic and less in other purpose, so that average number of daily travel is about 2 . This shows that the higher degree of job/housing balance will help improve the number of trips.

\section{Gravity Model Modification}

\subsection{Traditional Gravity Model}

We consider the attract strength and resistance between two traffic zone using traditional gravity model when predict distribution of trips. Just modeled on Newton's gravity model, the traffic volume between two zones is proportional to zones' trip generation and attraction while inversely proportional to the impedance. For trip distribution forecasts, there are following models:

$$
q_{i j}=k O_{i}^{\alpha} D_{j}^{\beta} f\left(c_{i j}\right)
$$

where, $O_{i}$ represents the trip generation in zone $i ; D_{j}$ represents the trip attraction in zone $j ; f\left(c_{i j}\right)$ is impedance function between zone $i$ and zone $j$; $\alpha, \beta$ is coefficient. 
This model is simple imitation of Newton's law of gravitation, so that the model itself doesn't satisfy constrains of conservation of traffic to anyone.

$$
q_{i j}=\frac{O_{i} D_{j} f\left(c_{i j}\right) K_{i j}}{\sum_{j} D_{j} f\left(c_{i j}\right) K_{i j}}
$$

where $K_{i j}$ is adjustment coefficient, and the calculation formula is:

$$
K_{i j}=\frac{\left(1-Y_{i j}\right) \lambda_{i j}}{1-Y_{i j} \lambda_{i j}}
$$

where, $\lambda_{i j}$ is the ratio of the actual traffic volume and calculated traffic volume which is between middle zone $i$ and $j ; Y_{i j}$ is the ratio of the actual traffic volume and generation traffic volume which is between middle zone $i$ and $j$.

This model can meet the trip generation constraints, That is $O_{i}=\sum_{j} q_{i j}$, So called single-constraint gravity model.

While meeting conservation conditions do not exist, so that gravity model is modified as following form:

$$
\begin{aligned}
& q_{i j}=K_{i} \cdot K_{j}^{\prime} \cdot P_{i} \cdot A_{j} \cdot f\left(c_{i j}\right) \\
& K_{i}=\left(\sum_{j} K_{j}^{\prime} \cdot A_{j} \cdot f\left(c_{i j}\right)\right)^{-1} \\
& K_{j}^{\prime}=\left(\sum_{i} K_{i} \cdot P_{i} \cdot f\left(c_{i j}\right)\right)^{-1}
\end{aligned}
$$

where, $q_{i j}$ is the predictive value of traffic volume between middle zone $i$ and $j(i$ is generating zone and $j$ is attracting zone); $c_{i j}$ is the traffic impedance between two zones; $P_{i}, A_{j}$ are the generation traffic volume of zone $i$ and attraction traffic volume of zone $j ; K_{p}, K_{j}$ are line constraints coefficient and row constraints coefficient.

Models have no human travel behavior analysis, so there is a deviation compared with the actual situation; typically, the distribution of people travel distance in the whole area is not a fixed value, while the gravity model look it as a given value; for different modes of transport models use the same travel time; it is difficult to determine the traffic volume within each zone; there is the possibility of exaggerated projections when transportation distance between zones is small.

Therefore, we can use the impact of residents travel distribution by job/housing balance to modify the traffic volume within middle zone and to optimizing the gravity model.

\subsection{Optimization Model}

\section{Step 1:}

Modify the traditional gravity model to the follow form:

$$
q_{i j}=k O_{i}^{\alpha} D_{j}^{\beta} f\left(c_{i j}\right) g\left(\varphi_{i}\right)^{\delta_{i j}}
$$

where $g\left(\varphi_{i}\right)$ is used to indicate the impact of job/housing balance of middle 
zone $i$ on demand; is a phase factor, it will be 1 if $i=j$, and be 0 otherwise. Here we assume that the internal traffic of middle zone $i$ is influence by its job/housing balance.

\section{Step 2:}

Using the following formula to determine the job/housing balance degree $\varphi_{i}$ of each middle zone:

$$
\varphi_{i}=\sqrt{\left(1-\left|1-2 k_{i}\right|\right) \cdot\left(1-\left|1-2 k_{i}^{\prime}\right|\right)}
$$

where, $\varphi_{i}$ is the job/housing balance degree of middle zone $i$.

$$
\begin{gathered}
k_{i}=\frac{N_{d}}{N_{d}+N_{e}} \\
k_{i}^{\prime}=\frac{A_{r}}{A_{m}}
\end{gathered}
$$

where, $N_{d}$ is the number of dwelling units. $N_{e}$ is the number of employment positions. $A_{r}$ is the value of residential land's area. $A_{m}$ is the value of middle zones' area. It is easy to see that if the number of dwelling units and the value of residents $i$ land's area are close to half of the zone, the job/housing balance degree will close to 1 . The degree will close to 0 if $k_{i}$ or $k_{i}^{\prime}$ is close to 0 or 1 .

\section{Step 3:}

Using the following formula to represent the $g\left(\varphi_{i}\right)$ :

$$
g\left(\phi_{i}\right)=\frac{2}{2-\phi_{i}} .
$$

Here we can see that the larger the degree of job/housing balance is, the bigger $g\left(\phi_{i}\right)$ is; and the value of is between 1 and 2, that is to say the formula will increase the forecast of internal traffic.

The modified model considerate the impact of job/housing balances on residents travel, so that the predictive value of internal travel will not be imprecise. It is certain practical significance.

\section{Model Application}

In Cangzhou residents travel volume forecasts, for example, the present volume of OD distribution is shown in Table 5.

We can get the predict OD distribution by traditional gravity model (TGM). Here just the internal traffic is shown as Table 6. It is easy to see that the errors of the internal traffic between predict value use TDM and the present value are very large in some zones. This is because of the deviation of the internal traffic length.

Now we can use the modified gravity model (MGM) which modified by the job/housing balance degree to predict the OD distribution. First we should calculate the value of $\phi_{i}$. The results are shown in Table 7.

Then we can get the predict OD distribution by MGM. Here also just the internal traffic is shown as Table 8. It is easy to see that the errors of the internal traffic between predict value use MDM and the present value in Zones 4 and 6 
are much smaller than the former ones (decreased $18.00 \%$ and 19.45\%). Although the relative errors in Zones 1 and 2 are increased, but the value of relative error increased are less than $3 \%$. The modified model is more accurate than the traditional one since the average relative error is reduced by $25.44 \%$.

Table 5. The present volume of OD distribution.

\begin{tabular}{|c|c|c|c|c|c|c|c|c|}
\hline $\mathrm{D}$ & 1 & 2 & 3 & 4 & 5 & 6 & 7 & Generation \\
\hline 1 & 118,809 & 3800 & 523 & 9567 & 21,314 & 3896 & 1432 & 159,341 \\
\hline 2 & 3863 & 247,950 & 3179 & 8236 & 47,141 & 8765 & 2729 & 321,863 \\
\hline 3 & 517 & 3283 & 130,260 & 4367 & 23,755 & 9123 & 1904 & 173,209 \\
\hline 4 & 9334 & 8180 & 4589 & 185,623 & 40,089 & 4213 & 3156 & 255,184 \\
\hline 5 & 22,469 & 45,242 & 22,477 & 41,970 & $1,759,905$ & 34,165 & 9618 & $1,935,846$ \\
\hline 6 & 3225 & 8860 & 9311 & 4249 & 35,572 & 158,699 & 1211 & 221,127 \\
\hline 7 & 1124 & 2147 & 1821 & 2920 & 9538 & 1286 & 80,145 & 98,981 \\
\hline Attraction & 159,341 & 319,462 & 172,160 & 256,932 & $1,937,314$ & 220,147 & 100,195 & $3,165,551$ \\
\hline
\end{tabular}

Table 6. The present volume of OD distribution based on TGM.

\begin{tabular}{ccccc}
\hline Zones & Present & TGM & Absolute error & Relative error \\
\hline 1 & 118,809 & 82,391 & 36,418 & $30.65 \%$ \\
2 & 247,950 & 240,615 & 7335 & $2.96 \%$ \\
3 & 130,260 & 144,563 & 14,303 & $10.98 \%$ \\
4 & 185,623 & 105,223 & 80,400 & $43.31 \%$ \\
5 & $1,759,905$ & $1,607,640$ & 152,265 & $8.65 \%$ \\
7 & 158,699 & 92,286 & 66,413 & $41.85 \%$ \\
Average & 80,145 & 93,300 & 13,155 & $16.41 \%$ \\
\hline
\end{tabular}

Table 7. The values $\phi_{i}$ in each middle zone.

\begin{tabular}{cccccccc}
\hline Middle zone & 1 & 2 & 3 & 4 & 5 & 6 & 7 \\
\hline$\phi_{i}$ & $0.20 \%$ & $24.49 \%$ & $47.75 \%$ & $54.77 \%$ & $83.90 \%$ & $68.64 \%$ & $36.88 \%$ \\
\hline
\end{tabular}

Table 8. The present volume of OD distribution based on MGM.

\begin{tabular}{ccccc}
\hline Zones & Present & MGM & Absolute error & Relative error \\
\hline 1 & 118,809 & 79,037 & 39,772 & $33.48 \%$ \\
2 & 247,950 & 235,807 & 12,143 & $4.90 \%$ \\
3 & 130,260 & 142,221 & 11,961 & $9.18 \%$ \\
4 & 185,623 & 138,651 & 46,972 & $25.31 \%$ \\
5 & $1,759,905$ & $1,675,904$ & 84,001 & $4.77 \%$ \\
7 & 158,699 & 123,143 & 35,556 & $22.40 \%$ \\
Average & 80,145 & 92,476 & 12,331 & $15.39 \%$ \\
\hline
\end{tabular}




\section{Conclusions}

This paper considers the job/housing balance and analyzes land use patterns of Cangzhou in old and new towns and residents travel characteristics. The results show that the travel time in new towns is higher than in old towns, and so is the average time of travel. In the old town, travelers prefer walking, cycling and public transport; the old towns which have mixed land use patterns get a higher proportion of travel internal. Therefore, it recommends that urban land expansion should reflect the concept of balance development; the mixed land use patterns promote the volume of traffic internal; the new towns should focus on providing more jobs which have low standard to travelers.

The modified gravity model (MGM) that is corrected by job/housing balance solves the problem of inaccurate internal traffic volume effectively. But the accuracy and reliability of the modified model need further verification, and the expression of job/housing balance degree using in this paper is just a simple form, and should be further improved.

\section{Acknowledgements}

This research was supported by the National Natural Science Foundation of China (51308018). We are very grateful for the comments from the anonymous reviewers.

\section{References}

[1] Howard, E. (1902) Garden Cities of Tomorrow. London.

[2] Downs, A. (1989) The Need for a New Vision for the Development of Large U.S. Metropolitan Areas. The Brookings Institution, New York.

[3] Cervero, R. (1989) Jobs-Housing Balancing and Regional Mobility. Journal of the American Planning Association, 55, 136-150. https://doi.org/10.1080/01944368908976014

[4] Cervero, R. (1995) Planned Communities, Self-Containment and Commuting: A Cross-National Perspective. Urban Studies, 32, 1135-1161. https://doi.org/10.1080/00420989550012618

[5] Cervero, R. (1991) Jobs/Housing Balance as Public Policy. Urban Land, 10, 4-10.

[6] Cervero, R. (1996) Jobs-Housing Balance Revisited: Trends and Impacts in the San Francisco Bay Area. Journal of the American Planning Association, 62, 492-511. https://doi.org/10.1080/01944369608975714

[7] Cropper, M.L. and Gordon, P.L. (1991) Wasteful Commuting: A Re-Examination. Journal of Urban Economics, 29, 2-13. https://doi.org/10.1016/0094-1190(91)90022-Y

[8] Deakin, E. (1989) Land Use and Transportation Planning in Response to Congestion Problems: A Review and Critique. Transportation Research Record, 1237, 7786.

[9] Mills, E. and Hamilton, B. (1984) Urban Economics.

[10] White, M.J. (1988) Urban Commuting Journeys Are Not "Wasteful". Journal of Political Economy, 96, 1097-1110. https://doi.org/10.1086/261579

[11] Peng, Z.R. (1997) The Jobs-Housing Balance and Urban Commuting. Urban Stu- 
dies, 34, 1215-1235. https://doi.org/10.1080/0042098975600

[12] Wachs, M., Taylor, B., Levine, N. and Ong, P. (1993) The Changing Commute: A Case-Study of the Jobs-Housing Relationship over Time. Urban Studies, 30, 17111729. https://doi.org/10.1080/00420989320081681

[13] Levingston, B.L. (1989) Using Job-Housing Balance Indicators for Air Pollution Control. Institute of Transportation Studies, University of California, Berkeley.

Submit or recommend next manuscript to SCIRP and we will provide best service for you:

Accepting pre-submission inquiries through Email, Facebook, LinkedIn, Twitter, etc. A wide selection of journals (inclusive of 9 subjects, more than 200 journals)

Providing 24-hour high-quality service

User-friendly online submission system

Fair and swift peer-review system

Efficient typesetting and proofreading procedure

Display of the result of downloads and visits, as well as the number of cited articles Maximum dissemination of your research work

Submit your manuscript at: http://papersubmission.scirp.org/

Or contact ojapps@scirp.org 